\title{
First tests of molybdenum mirrors for ITER diagnostics in DIII-D divertor
}

D. L. Rudakov, J. A. Boedo, R. A. Moyer, A. Litnovsky, V. Philipps, P. Wienhold, S. L. Allen, M. E.

Fenstermacher, M. Groth, C. J. Lasnier, R. L. Boivin, N. H. Brooks, A. W. Leonard, W. P. West, C. P. C. Wong, A.

G. McLean, P. C. Stangeby, G. De Temmerman, W. R. Wampler, and J. G. Watkins

Citation: Review of Scientific Instruments 77, 10F126 (2006);

View online: https://doi.org/10.1063/1.2336465

View Table of Contents: http://aip.scitation.org/toc/rsi/77/10

Published by the American Institute of Physics

\section{Articles you may be interested in}

Diagnostic first mirrors for burning plasma experiments (invited)

Review of Scientific Instruments 72, 475 (2001); 10.1063/1.1310580

Cleaning of first mirrors in ITER by means of radio frequency discharges

Review of Scientific Instruments 87, 11D439 (2016); 10.1063/1.4962055

Progress in preparing scenarios for operation of the International Thermonuclear Experimental Reactor Physics of Plasmas 22, 021804 (2014); 10.1063/1.4904015

VAPOR-LIQUID-SOLID MECHANISM OF SINGLE CRYSTAL GROWTH Applied Physics Letters 4, 89 (2004); 10.1063/1.1753975

The materials irradiation experiment for testing plasma facing materials at fusion relevant conditions Review of Scientific Instruments 87, 083502 (2016); 10.1063/1.4959201

Diagnostics for molybdenum and tungsten erosion and transport in NSTX-U

Review of Scientific Instruments 87, 11D445 (2016); 10.1063/1.4963146

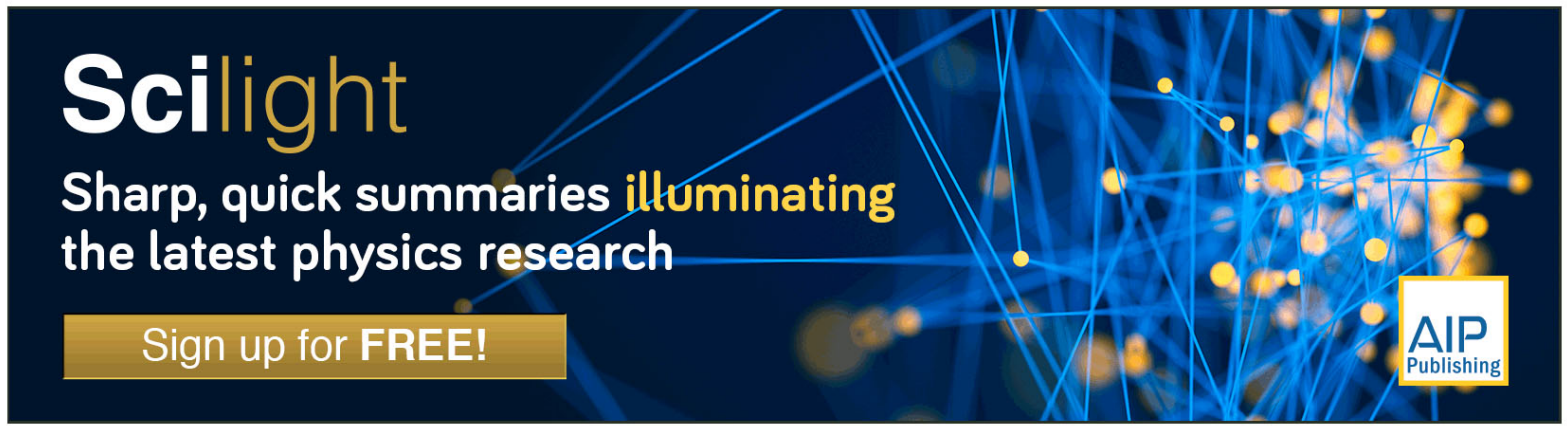




\title{
First tests of molybdenum mirrors for ITER diagnostics in DIII-D divertor
}

\author{
D. L. Rudakov, J. A. Boedo, and R. A. Moyer \\ Center for Energy Research, University of California, San Diego, La Jolla, California 92093-0417
}

A. Litnovsky, V. Philipps, and P. Wienhold

Institut für Plasmaphysik, Forschungszentrum Jülich, Association EURATOM-FZJ, D-52425, Jülich, Germany

S. L. Allen, M. E. Fenstermacher, M. Groth, and C. J. Lasnier

Lawrence Livermore National Laboratory, Livermore, California 94550

R. L. Boivin, N. H. Brooks, A. W. Leonard, W. P. West, and C. P. C. Wong

General Atomics, P.O. Box 85608, San Diego, California 92186-5608

\author{
A. G. McLean and P. C. Stangeby \\ Institute for Aerospace Studies, University of Toronto, Toronto, Ontario M3H 5T6, Canada \\ G. De Temmerman \\ Institute of Physics, University of Basel, Klingelbergstrasse 82, CH-4056 Basel, Switzerland
}

W. R. Wampler and J. G. Watkins

Sandia National Laboratories, Albuquerque, New Mexico 87185

(Received 5 May 2006; presented on 10 May 2006; accepted 10 July 2006; published online 17 October 2006)

Metallic mirrors will be used in ITER for optical diagnostics working in different spectral ranges. Their optical properties will change with time due to erosion, deposition, and particle implantation. First tests of molybdenum mirrors were performed in the DIII-D divertor under deposition-dominated conditions. Two sets of mirrors recessed $2 \mathrm{~cm}$ below the divertor floor in the private flux region were exposed to a series of identical, lower-single-null, ELMing (featuring edge localized modes) $\mathrm{H}$-mode discharges with detached plasma conditions in both divertor legs. The first set of mirrors was exposed at ambient temperature, while the second set was preheated to temperatures between 140 and $80{ }^{\circ} \mathrm{C}$. During the exposures mirrors in both sets were additionally heated by radiation from the plasma. The nonheated mirrors exhibited net carbon deposition at a rate of up to $3.7 \mathrm{~nm} / \mathrm{s}$ and suffered a significant drop in reflectivity. Net carbon deposition rate on the preheated mirrors was a factor of 30-100 lower and their optical reflectivity in the wave range above $500 \mathrm{~nm}$ was essentially preserved. (C) 2006 American Institute of Physics.

[DOI: $10.1063 / 1.2336465]$

\section{INTRODUCTION}

Optical diagnostics in ITER will rely on plasma facing mirrors to view the plasma. ${ }^{1,2}$ These so-called first mirrors (FMs) will be used over a wide wavelength range, from $\sim 5 \mathrm{~nm}$ up to $\sim 100 \mu \mathrm{m},{ }^{2}$ and will have to maintain good optical performance over prolonged time scales. FMs will be subject to intense irradiation in gamma, $\mathrm{x}$-ray and ultraviolet ranges, neutron damage, and bombardment by charge exchange atoms; they may also suffer from deposition of surface contaminants and dust, particularly in the divertor region where the neutral densities and local dust production rates are high. ${ }^{2}$ The current ITER divertor design incorporates carbon fiber composite tiles at the divertor targets. ${ }^{3}$ Carbon will be sputtered from the targets by physical and chemical erosions, then redeposited on the plasma facing components (PFCs), ${ }^{4}$ possibly including FM surfaces. Carbon film growth on FMs is a serious concern, since even thin films $(\sim 30 \mathrm{~nm})$ can dramatically reduce a mirror's reflectivity in the wavelength range below $700 \mathrm{~nm} .{ }^{5}$ Dedicated experiments in tokamak divertors are needed to determine the deposition rates in present day machines and models need to be developed to extrapolate the results to plasma conditions expected in ITER. Deposition mitigation and mirror cleaning techniques have to be established. Here we report on the first tests of ITER-candidate molybdenum mirrors performed in the divertor of the DIII-D tokamak and a successful attempt to mitigate the carbon deposition on the mirrors by controlling the mirror temperature.

\section{EXPERIMENTAL SETUP}

DIII-D ${ }^{6}$ is a large tokamak $(R=1.67 \mathrm{~m}, a=0.67 \mathrm{~m})$ with all-carbon (graphite) PFCs. Plasma-material interactions in the lower divertor of DIII-D are studied using the divertor material evaluation system (DiMES). ${ }^{7}$ DiMES allows insertion of material samples into the lower divertor floor, exposing them to either a single plasma discharge, or a series of reproducible discharges to increase the total exposure time. The DiMES mechanical drive is actuated by a hydraulic system; its design incorporates 12 electrical leads connected via a vacuum electrical feedthrough, allowing the use of instrumented samples. Two of the connections are made of thermocouple grade materials throughout the drive and are used for an $E$-type thermocouple. The system has been recently 


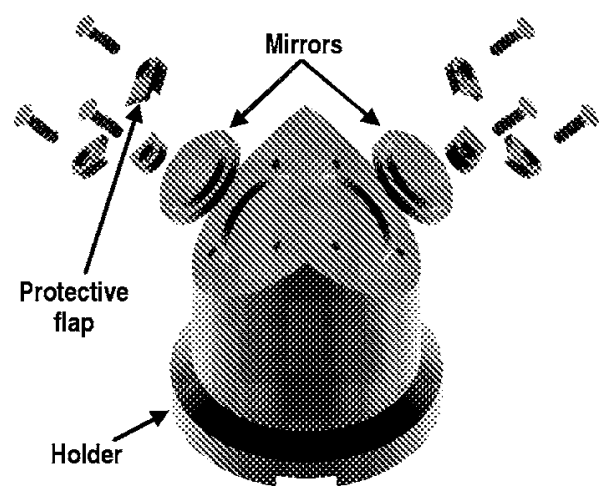

FIG. 1. Mirror holder DiMES head.

upgraded to allow for in situ temperature control of the samples. It relies on an OMEGA CN77000 temperature controller which reads the sample temperature with a thermocouple and controls power to a high-vacuum-compatible cartridge heater built into the sample holder (also referred to as the DiMES head).

A specially designed mirror holder head shown in Fig. 1 was used for the experiments described below. It was made of type 316 stainless steel and featured a built-in heater (OMEGA CSH-301335/120V, rated to $335 \mathrm{~W}$ and maximum temperature of $760{ }^{\circ} \mathrm{C}$ ), and a thermocouple (OMEGA CXSS-040E-6-SHX, rated to $650{ }^{\circ} \mathrm{C}$ ). The base of each mirror was held by three stainless steel clamps, one of which had an extended flap which masked an area of about $3 \times 8 \mathrm{~mm}^{2}$ (Fig. 1). This protected spot was used for reference during the analysis of the exposed mirrors. The mirrors were made of single-crystal molybdenum with the reflective surface roughness of less than $10 \mathrm{~nm}$. The mirrors were $4 \mathrm{~mm}$ thick; the diameters of the base and reflective surface were 22 and $18 \mathrm{~mm}$, respectively (Fig. 1).

The geometry of the exposure is illustrated in Fig. 2. The mirror holder was inserted through a port hole in the divertor floor, its top edge positioned $1 \mathrm{~cm}$ below the floor surface. The top edge was oriented perpendicular to the magnetic field, so that the two mirrors faced opposite toroidal directions. The mirrors were exposed in lower single null (LSN) magnetic configuration discharges and located in the private flux zone during the exposure. The deuteron flow to the divertor floor was in the direction of $B$ shown in Fig. 2(b) (as confirmed by Mach probe measurements); consequently, the left mirror in the figure will be referred to as "upstream" and
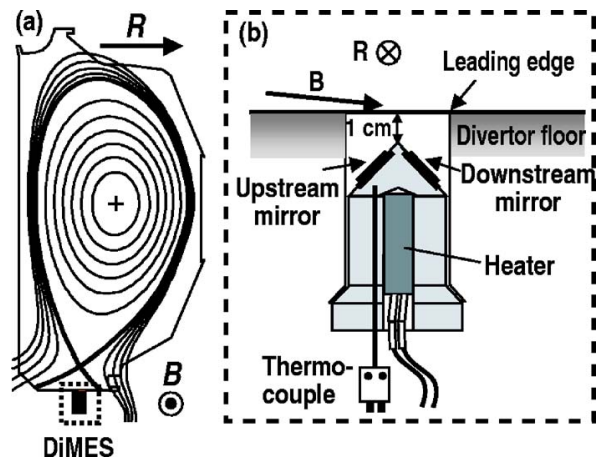

FIG. 2. Mirror exposure geometry.

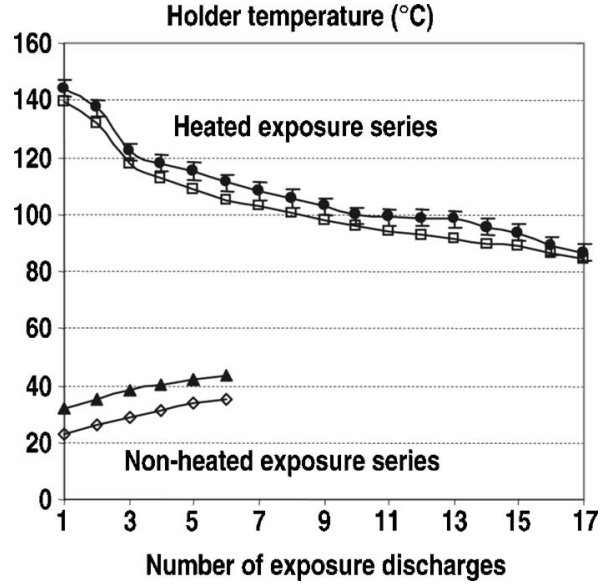

FIG. 3. Bulk temperature of the mirror holder before (open symbols) and after (solid symbols) the plasma exposures.

the right one as "downstream." The incidence angle of the plasma flux on the floor surface at the DiMES radial location was less than $1^{\circ}$.

\section{EXPERIMENTAL RESULTS}

Two sets of mirrors were exposed on two consecutive days to highly reproducible ELMing (featuring edge localized modes) H-mode LSN discharges in deuterium. The discharge parameters were: toroidal magnetic field, $B_{T}=2 \mathrm{~T}$, plasma current, $I_{p}=1.1 \mathrm{MA}$, neutral beam heating power, $P_{\mathrm{NBI}}=6.6 \mathrm{MW}$, and average plasma density, $\bar{n}_{e}=8 \times 10^{19} \mathrm{~m}^{-3}$. The divertor was detached and plasma temperature and density in the private flux zone near the floor were $T_{e}=0.5-2 \mathrm{eV}$ and $n_{e}=(4-8) \times 10^{20} \mathrm{~m}^{-3}$. Between shots the mirror holder was partially retracted (about $10 \mathrm{~cm}$ below the divertor floor) to prevent erosion/deposition by the intershot helium glow discharge.

The first set of mirror samples was exposed to six plasma discharges for a total time of about $25 \mathrm{~s}$. No active temperature control was used, but the holder and the mirrors were heated by the plasma radiation and charge exchange atom fluxes. At the beginning of the exposure the holder temperature was $23{ }^{\circ} \mathrm{C}$. After each exposure discharge the temperature had increased by about $9^{\circ} \mathrm{C}$ (as measured $30 \mathrm{~s}$ after the discharge to avoid pickup from the decaying magnetic fields); it then decreased slowly during the $10 \mathrm{~min}$ interval between shots. By the end of the sixth exposure discharge, the holder temperature was at about $44{ }^{\circ} \mathrm{C}$ (Fig. 3).

Upon removal from the vacuum chamber, visible deposits were found on both mirrors [Figs. 4(a) and 4(b)], holder, and clamps. There was a strong asymmetry in the deposition between the upstream and downstream mirrors. The deposition on the upstream mirror was rather uniform, while on the downstream mirror a clear gradient was observed, with heaviest deposits near the top of the mirror. This was probably caused by redeposition of the carbon sputtered locally from the leading edge of the downstream graphite tile. The aerial carbon coverage, measured by secondary ion mass spectroscopy (SIMS) and nuclear reaction analysis (NRA), ${ }^{8}$ was comparable in the centers of the upstream and downstream mirrors, while at the top of the downstream mirror it 


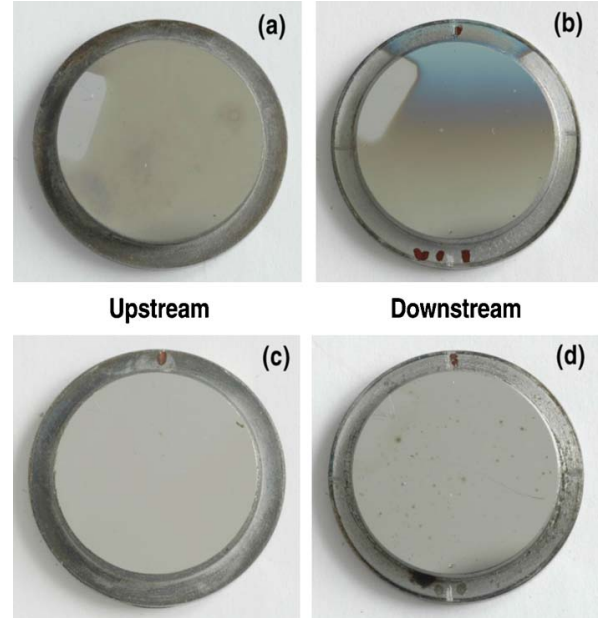

FIG. 4. Mirrors exposed at ambient [(a) and (b)] and elevated [(c) and (d)] temperatures.

was a factor of 2 higher. The thickness of the deposited hydrocarbon film was largest near the top of the downstream mirror; its value of $93 \mathrm{~nm}$ measured by spectroscopic ellipsometry corresponds to a net deposition rate of $3.7 \mathrm{~nm} / \mathrm{s}$. The $\mathrm{D}: \mathrm{C}$ ratio in the film was about 0.5 , as measured by NRA.

Laboratory experiments with thermal ion beams have shown that the chemical erosion rate of carbon peaks at about $400{ }^{\circ} \mathrm{C}$, where it is about an order of magnitude higher than at room temperature. ${ }^{9,10}$ In order to mitigate the carbon deposition by chemical reerosion, in the course of the second exposure the mirrors were kept at elevated temperature using the internal heater. The temperature controller was set to maintain the holder temperature at $400{ }^{\circ} \mathrm{C}$, but the heater failed overnight and there was no possibility to replace it before the experiment. Fortunately, the cooling rate of the holder was rather slow and the temperature was still elevated at the beginning of the experiment. The heated set of mirrors was exposed to 17 plasma discharges similar to those employed with the first set, for a total time of about $70 \mathrm{~s}$. The holder temperature at the start of the plasma exposure was at $140{ }^{\circ} \mathrm{C}$ and decreased slowly throughout the experiment. By the end of the exposure the holder temperature was about $84^{\circ} \mathrm{C}$. As in the nonheated exposure, the holder temperature increased slightly after each exposure discharge (Fig. 3). Error in the measurement of the temperature increase in this case was estimated to be $\pm 3{ }^{\circ} \mathrm{C}$ (error bars in Fig. 3).

When the holder with mirrors was removed from DiMES there were no visible deposits on either of the mirrors [Figs. 4(c) and 4(d)]. Low carbon content on the heated mirror surfaces was confirmed by SIMS and NRA analyses. The aerial carbon density on the heated mirrors from NRA was a factor of 10-30 lower than on the nonheated ones. Considering that the total exposure time of the heated mirrors was almost three times longer, this corresponds to the net carbon deposition rate being lower by a factor of 30-100.

Figure 5 shows the total reflectivity measured in the centers of the heated and nonheated downstream mirrors before and after the exposures. In both cases the reflectivity for wavelengths greater than $1200 \mathrm{~nm}$ was virtually unaffected by the exposures. For wavelengths below $1000 \mathrm{~nm}$ the re-

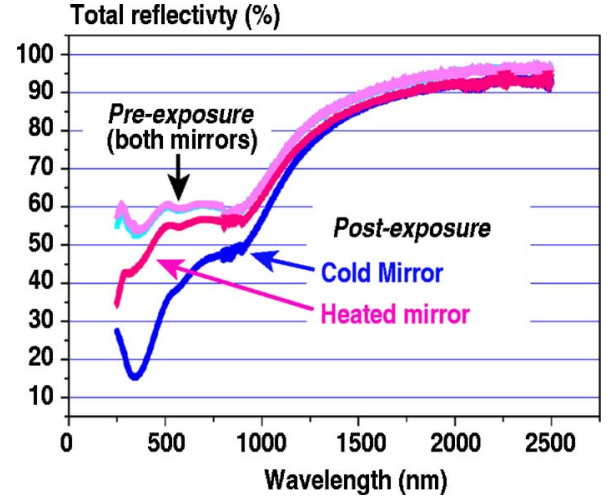

FIG. 5. Total reflectivity of the heated and nonheated downstream mirrors before and after the exposures.

flectivity was reduced on both mirrors, but the reduction on the heated mirror was much smaller. X-ray photoelectron spectroscopy measurements revealed that the decrease of the heated mirror reflectivity in the wavelength range below $500 \mathrm{~nm}$ was caused by surface oxidation. It is presently unclear whether the oxidation of the heated mirrors was predominantly from the plasma exposure or from the long-term storage in air. Thin $(<15 \mathrm{~nm})$ oxide films were found on both heated and nonheated mirrors despite the hydrogen glow discharge cleaning prior to the exposure in DIII-D.

\section{DISCUSSION AND SUMMARY}

Our experiments have confirmed that diagnostic mirrors located in close proximity to the divertor plasma of a tokamak with carbon PFCs are likely to suffer from carbon deposition leading to degradation of their reflectivity. We have also shown that a moderate increase in the temperature of the mirrors acts to mitigate the deposition and preserve the reflectivity, at least in the wavelength range above $500 \mathrm{~nm}$. We should stress that the thermocouple measured the bulk temperature of the mirror holder, not that of the mirrors themselves. The fact that the deposition mitigation was achieved at seemingly low temperatures could be explained by the mirror surface temperature being significantly above the measured bulk temperature during the plasma discharges. As described above, an increase of the head bulk temperature by about $9{ }^{\circ} \mathrm{C}$ was observed after each plasma discharge during the nonheated exposure (Fig. 3). With the mass of the holder being about $1 \mathrm{~kg}$ and heat capacity of stainless steel being about $0.5 \mathrm{~J} / \mathrm{g} \mathrm{K}$, this corresponds to an absorbed energy of $4.5 \mathrm{~kJ}$. This in turn corresponds to absorbed power flux of about $70 \mathrm{~W} / \mathrm{cm}^{2}$ on the projected plasma-facing area of the mirror holder, which is in good agreement with radiated power measurements in partially detached DIII-D divertor. ${ }^{11}$ The radiated power spectrum in DIII-D divertor is dominated by strong lines of carbon (C IV, $155 \mathrm{~nm}$ and C III, $117.5 \mathrm{~nm}$ ) and deuterium (Ly- $\alpha, 121.6 \mathrm{~nm}) .{ }^{11}$ Assuming the average mirror reflectivity over this wavelength range to be $40 \%$ (Ref. 12) and the holder reflectivity to be negligible (the holder surface was not polished), and neglecting the heat transfer from the mirrors to the holder during the plasma discharge, the mirror temperature rise by the end of each exposure discharge in the nonheated series would be about 
$140{ }^{\circ} \mathrm{C}$. Measurements of the postdischarge temperature rise during the heated exposure were less accurate; however, there is no reason to expect the radiation heating of the mirrors to be significantly different between the two exposure series. Therefore, we conclude that the mirror surface temperatures at the end of each heated exposure discharge may be as high as $220-280{ }^{\circ} \mathrm{C}$, which is closer to the temperature where the chemical erosion yield peaks. ${ }^{9,10}$ We should note that the above estimate is high-bound since the finite heat conductivity of the mirror holder was not accounted for. ANSYS heat transfer modeling is underway to more accurately estimate the mirror surface temperature rise during an exposure discharge. In any case, it is quite remarkable that the average temperature difference of just about $70^{\circ} \mathrm{C}$ between the two mirror sets resulted in such a strong decrease of the net carbon deposition rate.

\section{ACKNOWLEDGMENTS}

This work was performed in the framework of bilateral U.S.-EURATOM Exchange Program and supported in part by the U.S. Department of Energy under Grant Nos. DEFG02-04ER54758, W-7405-ENG-48, DE-FC02-04ER54698, and DE-AC04-94AL85000.

${ }^{1}$ A. E. Costley D. J. Campbell, S. Kasai, K. E. Young, and V. Zaveriaev Fusion Eng. Des. 55, 331 (2001)

${ }^{2}$ V. Voitsenya et al., Rev. Sci. Instrum. 72, 475 (2001).

${ }^{3}$ R. Aymar, P. Barabaschi, and Y. Shimomura Plasma Phys. Controlled Fusion 44, 519 (2002).

${ }^{4}$ G. Federici et al., Nucl. Fusion 41, 1967 (2001).

${ }^{5}$ P. Wienhold et al., J. Nucl. Mater. 337-339, 1116 (2005).

${ }^{6}$ J. L. Luxon, Nucl. Fusion 42, 614 (2002).

${ }^{7}$ C. P. C. Wong, D. G. Whyte, R. J. Bastasz, J. Brooks, W. P. West, and W. R. Wampler, J. Nucl. Mater. 258-263, 433 (1998).

${ }^{8}$ W. R. Wampler, S. L. Allen, A. G. McLean, and W. P. West, J. Nucl. Mater. 337-339, 134 (2005).

${ }^{9}$ J. W. Davis, A. A. Haasz, and P. C. Stangeby, J. Nucl. Mater. 155-157, 234 (1988).

${ }^{10}$ E. Vietzke and V. Philipps, Fusion Technol. 15, 108 (1989).

${ }^{11}$ R. C. Isler, R. W. Wood, C. C. Klepper, N. H. Brooks, M. E. Fenstermacher, and A. W. Leonard, Phys. Plasmas 4, 355 (1997).

${ }^{12}$ Handbook of Chemistry and Physics, 84th edition, edited by D. R. Lide (CRC, New York, 2003), pp. 12-142. 